\title{
articles
}

\section{Self-concept in overweight adolescents}

\section{Sandra Vuk Pisk, MD \\ Mate Mihanović, PhD \\ Ante Silic, MD}

Anamarija Bogović, Psychologist

Psychiatry Hospital Sveti Ivan, Zagreb, Croatia

\section{Vesna Vidovic, PhD}

Clinical Hospital Center - Zagreb, Clinic for Psychological Medicine, Zagreb, Croatia

Background and objective. Adolescence is considered a critical stage of life, and one during which body image and self-concept are of particular importance for peer acceptance and approval. Body weight may impact on satisfaction or dissatisfaction in adolescent girls' self-concept. The aim of this research was to determine the association between obesity and self-concept among adolescent girls.

Methods. The study sample consisted of 40 overweight (BMI 25 -30) 18-year-old girls in their last year of high school. A further 40 girls of the same age with a BMI of $18-25$ formed a control group. The Offer Self-Image Questionnaire for Adolescents (OSIQ) was used to evaluate their self-concept. Descriptive statistical methods used in analysing the data included calculation of the median and standard deviation of variables, and $t$-tests were used to compare group differences, with $p<0.05$ taken as the level of significance.

Results. Statistically significant differences between two groups were found in two components of the OSIQ, sexual attitudes ( $p=0.044)$ and psychopathology $(p=0.020)$, but no differences were found in other components such as impulse control, emotional tone, body and self-image, social relations, morals, family relations, mastery of the external world, vocational educational goals and superior adjustment.

Conclusion. Our results suggest that overweight adolescent girls are less adjusted with regard to their sexual attitudes and present with more psychopathology as measured by the OSIQ compared with their peers of average weight.

The prevalence of overweight and obesity among children, adolescents and adults appears to be increasing, both in Europe and the USA. ${ }^{1-3}$ According to some research data, approximately $31 \%$ of children and adolescents (age 6 - 19 years) worldwide are overweight, while other studies state that $25 \%$ of the adolescent population (age 14 - 17) is overweight., Figures are similar for the USA and Europe. ${ }^{3}$

Research in Croatia showed $41 \%$ of the study population 18 65 years of age to be overweight. ${ }^{6}$ Although there are minor differences, all the studies we reviewed have shown significant proportions of overweight adolescents, with the prevalence increasing over the past 30 years. ${ }^{1,7,8}$

Together with increasing obesity in this population, it is becoming evident that stigmatisation of overweight adolescents is very common in many settings, including by family members, peers and even educators. ${ }^{9}$

Western culture encourages personal responsibility in many walks of life, including control of body weight. ${ }^{9-13}$ Fowler cites a number of studies in the US reporting discrimination against obese adolescents, both by their peers and by others. ${ }^{14}$ Obese adolescents are often excluded from the social, sport and other activities of their peer group. $12,13,15,16$

The intense psychological, emotional, intellectual and social changes that characterise adolescence make it an extremely vulnerable phase of development, during which numerous subconscious conflicts need to be resolved and both personal identity and adequate socialisation established. ${ }^{10-13,16,17}$ Peer acceptance becomes of extreme importance, ${ }^{16-18}$ and peer rejection and stigmatisation may have a profound impact on an adolescent's psychological status. ${ }^{19}$ While belonging to the peer group promotes feelings of safety and securty, peer rejection (real or imaginary), may create feelings of inferiority and low self-esteem. 16-18,20 Some studies have shown that obesity may be related to a deterioration in quality of life of adolescent girls. ${ }^{16,19}$

In Western culture, a slim female figure is seen as ideal. Research has shown that adolescent girls are becoming increasingly preoccupied by their body image and burdened with the beauty ideal imposed by the media and society. ${ }^{11-13,21,22}$ Body dissatisfaction in adolescent girls may imply development of negative self-perception and self-evaluation, which can result in development of adolescent depression and eating disorders. $12,13,22-24$

The need to accept a body image that is changing radically from that of childhood is actualised in the adolescent period. ${ }^{16-18}$ It has been established that in adolescence, popularity in the peer group becomes increasingly dependent on body image. It has also been found that more active adolescents have more positive self-concept. 16,18,25,26 While social relationships with others are very important in the development of self-concept, self-concept does not only result from independent self-evaluation and evaluation of real interactions with others, but also from symbolic interactions, or ideas about possible judgements of others. Also, in the development of self-concept not all people with whom the person has social relationships are equally important. There are 'significant others', defined as the most important individuals in this development process.

Self-concept is a multidimensional construct. It is defined as individual evaluation of cumulative successes and mistakes, as well 
as subjective evaluation of personal potential. ${ }^{16}$ Potentials are not only descriptors of athletic or intellectual capabilities, but of physical characteristics as well. ${ }^{16,18,20}$

In 1962, Offer constructed the Offer Self-Image Questionnaire for Adolescents (OSIQ) for the purpose of systematic psychological assesment.27,28 This self-descriptive questionnaire was intended to evaluate adolescent functioning in many dimensions, as adolescents may be well adjusted in some aspects of their world, while having adjustment problems in others. ${ }^{27,28}$

\section{Aims and objectives}

The aim of our study was to determine whether there are differences in self-concept between overweight and average-weight female adolescents. Our hypothesis was that overweight adolescent girls and their average-weight peers differ in relation to self-concept, and more specifically that being overweight has a negative impact on the self-concept of adolescent girls.

\section{Subjects and methods Subjects}

The research sample consisted of 80 18-year-old female students in their last year of high school, separated into study and control groups. The study group comprised 40 overweight girls a with body mass index (BMI) between 25 and 30, and the control group 40 girls of average weight with a BMI between 18 and 25 .

The study took place during the second half of 2001 in various high schools in the Hrvatsko Zagorje region, north-western Croatia. Only female adolescents, 18 years of age and in the last year of high school, were included, selection criteria being based on BMI measurements. BMI measurements were done on a total of 181 girls, 40 of whom had a BMI of $25-30$ (overweight) and 10 a BMl of $<18$ (underweight). BMls for the remaining 131 girls were between 18 and 25 (average weight). Using a random choice method, 40 of the average-weight girls were selected for the control group.

None of the girls who took part in the study had any significant medical conditions, no psychiatric or somatic diagnoses were recorded, their menstrual cycles were regular, and they were not taking regular medication. All signed an informed consent document before entering the study, in accordance with the legislation of the Croatian Ministry of Health. ${ }^{29}$ Criteria for inclusion in the study group were overweight female adolescents aged 18 years of age with a BMI of $25-30$, who gave informed consent.

\section{Methods}

We evaluated self-concept of study participants using the OSIQ, constructed to measure descriptive aspects of self-image in adolescents from 13 to 19 years of age.

Reliability and validity of the OSIQ have been tested on several studies of US adolescents. Cronbach alpha values, with the scales applied in the group of older adolescents, have been reported as
$0.8-0.88$. Reliability of the test-retest type of measurements, taken 6 months apart, has been reported as 0.73 for the entire result of the questionnaire. ${ }^{16,27,30}$ The discriminatory OSIQ value has been checked in a number of studies, with study samples including healthy, sick, disabled and delinquent adolescents. The OSIQ has also been verified in cross-cultural studies, ${ }^{16,27,31-33}$ and in adolescents in Croatia. ${ }^{34}$

In the original OSIQ, Offer took into consideration different variables, such as sex, age and the year of testing. We have used the version of the questionnaire adjusted for female adolescents. It consists of 130 items (simple statements), intended to measure adjustments in 11 content areas that are considered important in the psychological world of adolescents. These 11 content areas are grouped in 5 subscales, presenting 5 separate self-aspects: Psychological Self, Social Self, Familial Self, Sexual Self and Coping Self.

Psychological Self (PS) involves the adolescent's emotions, wishes and fantasies. It comprises 3 of the 11 OSIQ content areas. The first content area of the psychological self is impulse control, measuring how strong the adolescent feels while under emotional pressure (e.g. 'Even under pressure I manage to remain calm'). The second content area of the psychological self is emotional tone, measuring the rate of affective harmony and stability. The third content area of the psychological self is bodily self, indicating how the adolescent relates to his/her own body.

Social Self (SS) involves perceived relationships with others, moral perception, and educational and professional goals. It comprises another 3 of the 11 OSIQ content areas: social functioning, ethical values (moral scale, reflecting super-ego development), and vocational attitudes (educational and professional goals - perceived readiness in planning the subject's professional future). This aspect of the self is primarily described by the social functioning scale. The 2 remaining scales measure super ego development (moral scale - ethical values scale) and the adolescent's educational and professional goals and perceived readiness for future planning of a profession (vocational attitudes scale).

Sexual Self (SxS) includes perceived functioning of female adolescent sexuality, with emphasis on instinctive and social behaviour adjustment. Balance with regard to the sexual impulses and their socially acceptable expressions is emphasised. Aspects of adolescents' sexual activity seem to relate strongly to aspects of their home life and scholastic status. They are also likely to have internalised the values of their parents with respect to their own behaviour. According to Offer, ${ }^{32}$ in a group of teenagers who perceived their parents as getting along very well, $47 \%$ had had intercourse; among those who perceived their parents as not getting along well, $68 \%$ had had intercourse. It is therefore evident that the adolescent's home environment has an important effect on sexual behaviour. This aspect of self is measured with the sexual attitudes scale. According to Offer, ${ }^{27,28}$ adolescents are relaxed with regard to sexual attitudes and not afraid of sexual behaviour; they 
report satisfaction with their body changes, talking of easy transition towards active sexuality. Most adolescents consider it important to have friends of the opposite sex.

Familial Self (FS) involves the field that is, according to Offer, a crucial one and the most responsible for the psychological state of the adolescent. This aspect is measured through the family attitudes (i.e. the attitudes of the adolescent towards the family). Most adolescents in Offer's study ${ }^{27}$ considered that major intergenerational conflicts do not exist, and they did not perceive any major problems in the relationships between their parents and themselves.

Coping Self (CS) involves perceived personal abilities to face the difficulties of life. The adaptable coping self comprises 3 OSIQ content areas, the first being self-confidence, i.e. coping with the outside world (how the adolescent copes with imposed assignments), the second mental health and psychopathology, i.e perceived presence of psychopathology in the form of abnormal/ maladaptive behaviour (psychopathological symptoms are listed on a psychopathology scale), and the third self-reliance/optimal adjustment, i.e. coping with themselves, significant others and the world in general ('ego strength measure').

According to Offer, ${ }^{27,28}$ the majority of adolescents deny existence of the psychopathology symptoms. However, a minority of adolescents consider themselves as emotionally empty, with life being just a long line of problems with no solution in sight. This group of adolescents is reported to be confused most of the time about common issues such as functioning in school, and relations within their peer group and friends.

Normal adolescents, according to Offer, ${ }^{20}$ are 'adolescents who are free from disturbing physical, psychological, and social signs and symptoms'. Normal adolescents do not experience the psychopathological symptoms listed on the psychopathology scale. Psychopathology includes deviation from adaptive behaviour, deviation from adequate social functioning, and lack of enjoyment in relating to their peer group and family, as well as denial of social values in general. Psychopathology includes psychiatric symptoms and disorders, such as dysphoria, tension, anxiety and personality disorders. It also includes symptoms such as a feeling of shame, when adolescents want to hide in a corner and cry, feelings of not being loved, feelings of feeling confused most of the time, feelings of life being just a long line of problems without adequate solutions, and feelings of fear that are beyond their understanding.

In all the 11 OSIQ content areas, half of the items are formulated as positive and the other half as negative. The adolescent is required to indicate to what extent each statement applies to him or her, choosing from six answers, each of which has a corresponding numerical value, as follows: 1. I completely agree; 2. I agree; 3. I somewhat agree; 4. Not completely true; 5 . Not true; 6.1 completely disagree. ${ }^{27,28}$
Descriptive statistical methods were used, with the median and standard deviation (SD) of variables calculated. Pairs of means were compared using the $t$-test, with $p<0.05$ taken as significant.

\section{Results}

Table 1 shows that for both groups the highest overall scores were recorded in the FS scale. While median values for all scales ranged between 20 and 30, FS scales in both groups exceeded 40.

The $t$-tests results showed statistically significant differences between the overweight (trial group) and average-weight (control group) adolescents for two subscales, the SS subscale sexual attitudes $(p=0.044)$ and the CS subscale psychopathology $(p=0.020)$.

\section{Discussion and conclusions}

Our results lead us to conclude that the overweight adolescent girls who participated in our study seem to be less comfortable in terms of their sexual attitudes and to perceive that they have more symptoms of psychopathology than their peers of average weight. Specifically, the overweight girls feel intimidated by their sexual impulses, dislike their body changes (feeling negative about their own bodies, and convinced that they are unattractive), are negative about their secondary sexual characteristics (e.g. thinking that their breasts are too large), feel confused about body boundaries, experience difficulties with the transition to active sexuality, and do not consider having intimate friends to be important. Psychopathological symptoms reported by the overweight girls include fear of being ridiculed, feelings of confusion and emotional emptiness.

We were not able to compare our results with similar research, as we have not been able to identify any published studies in which

\section{Table 1. OSIQ results for the study and control groups}

\begin{tabular}{|c|c|c|c|c|c|}
\hline \multirow[b]{2}{*}{ OSIQ scales } & \multicolumn{2}{|c|}{$\begin{array}{l}\text { Study group } \\
\qquad N=40\end{array}$} & \multicolumn{2}{|c|}{$\begin{array}{c}\text { Control group } \\
\qquad N=40\end{array}$} & \multirow{2}{*}{$\begin{array}{c}p \\
(t \text {-test) }\end{array}$} \\
\hline & Mean & SD & Mean & SD & \\
\hline PS-1 impulse control & 25.7 & 7.28 & 25.37 & 6.48 & 0.834 \\
\hline PS-2 emotional tone & 28.3 & 8.84 & 25.42 & 7.30 & 0.114 \\
\hline PS-3 body and self-image & 25.6 & 6.89 & 22.7 & 6.13 & 0.052 \\
\hline SS-1 social relations & 20.9 & 6.60 & 19.3 & 6.57 & 0.259 \\
\hline SS-2 morals & 25.9 & 4.38 & 27.7 & 6.64 & 0.163 \\
\hline $\begin{array}{l}\text { SS-3 vocational-educational } \\
\text { goals }\end{array}$ & 22.0 & 6.28 & 20.7 & 6.17 & 0.353 \\
\hline SXS sexual attitudes & 31.6 & 7.20 & 28.6 & 5.71 & $0.044^{*}$ \\
\hline FS family relations & 53.6 & 17.75 & 46.8 & 17.29 & 0.087 \\
\hline $\begin{array}{l}\text { CS-1 mastery of the external } \\
\text { world }\end{array}$ & 25.8 & 5.37 & 24.3 & 7.18 & 0.286 \\
\hline CS-2 psychopathology & 37.8 & 9.20 & 32.9 & 9.29 & $0.020^{*}$ \\
\hline CS-3 superior adjustment & 42.8 & 8.95 & 39.2 & 7.72 & 0.056 \\
\hline
\end{tabular}


the OSIQ has been used for a similar population and with same hypothesis. Subjects in previous studies that have used the OSIQ have included adolescent girls suffering from depression, with divorced parents, and prior to their first employment. Others have used the questionnaire to study the impact of key life factors and a disturbed self-image, e.g. in adolescents suffering from anorexia or bulimia, suicidal adolescents, or adolescents in migrating populations. $^{35-44}$

Studies using the Youth Self Report, SDQ, YEDE-Q, EES-C and SRQ-20 reported overweight male and female adolescents as having psychopathological symptoms, suffering more from mental disorders, and reporting body dissatisfaction and problems in psychosocial functioning. ${ }^{45-49}$

The inadequate adjustment in sexual attitudes revealed by the overweight adolescent girls in our study could be a result of dissatisfaction with their bodies, resulting in feelings of unattractiveness in comparison with the cultural 'standards' imposed by Western society. ${ }^{11,12,21,22,25}$ Adolescent girls are reported to be preoccupied with their body weight and body image. 11,12,14,16,25 They strive to achieve socially imposed 'ideal' body proportions, valuing themselves only in relation to their appearance. 11-13,16,22,25,26

Some studies point out that overweight female adolescents suffer from low self-esteem, which can be related to their concept of body image. ${ }^{11-13}$ Several studies report the impact of body image on selfconcept to be much stronger in female than in male subjects. ${ }^{11,12,16,22,24}$ It has been observed that self-concept directly correlates with their perception of their personal attractiveness. ${ }^{16,22}$ In Western culture, obesity is viewed as an abnormal and therefore stigmatised condition, and this can lead to marginalisation of obese people. 9,10,11,16

With regard to the cultural perceptions of body image mentioned above, our study suggests that differences on the psychopathology scale may be interpreted in relation to dissatisfaction with body image and negative self-image of overweight adolescent girls, who feel that they are being negatively perceived by others.

As they develop, adolescent girls continually compare themselves with their peers. This may lead to severe frustration when a girl sees herself as significantly different from other girls. ${ }^{11-13,16}$ The psychopathology scale in the OSIQ underlines the status of overweight adolescent girls: with their fear of being ridiculed by others, feelings of confusion and guilt, and exaggeration of the size of their sexual organs, overweight adolescent girls may experience strong feelings of inadequacy, and feel that they need to hide away. ${ }^{27,28}$ With Western culture holding overweight persons responsible for their appearance, they are not only accused of having poor self-control, but are often discriminated against and treated as incompetent. 9,10,12,16

The fact that overweight adolescent girls and their averageweight peers differ significantly with regard to the sexuality and psychopathology scales of the OSIQ partially confirms our hypothesis that differences in self-concept do exist between the two groups. Statistically significant differences in other aspects of the OSIQ might be lacking because body image dissatisfaction and body image comparisons with peers are the key factors responsible for differences in OSIQ sexuality and psychopathology scales.

In contrast to the above, other components of self-confidence primarily depend on chronological age and how unconscious conflicts of the adolescent period, not limited by appearance and body image perception, are dealt with. ${ }^{18,32}$ These conflicts become the most important source of identity crisis. Difficulty in achieving a well-balanced self-image, along with social pressures, often damages self-confidence, which improves only later in adolescence. A limitation of our study is the relatively small sample size. For this reason, we believe that our findings should not be applied to the broader population of overweight adolescent girls. Those doing further research in this field should increase the number of study participants, include male adolescents, and extend the age of adolescents taking part in the study.

\section{References}

1. Lobstein T. Prevalence and costs of obesity. Medicine 2011;39:11-13.

2. Alton I. The overweight adolescent. In: Stang J, Story M, eds. Guidelines for Adolescent Nutrition Services. Minneapolis, MN: Center for Leadership, Education and Training in Maternal and Child Nutrition, Division of Epidemiology and Community Health, School of Public Health, University of Minnesota, 2005.

3. Zaborskis A, Petronyte G, Sumskas L, Kuzman M, lannotti RJ. Body image and weight control among adolescents in Lithuania, Croatia, and the United States in the context of global obesity. Croat Med J 2008:49:232-242.

4. Karšić M. Učestalost prekomjerne tjelesne težine i prehrambene navike učenika u dvije osnovne škole Osječko-baranjske županije (Frequency of the overweight and nutritional habits of students in two elementary schools in Osijek-baranja country). Hrvatski časopis za javno zdravstvo 2008;4:11-18.

5. American Obesity Association. AOA Fact Sheets. Obesity in Youth. http://obesity tmghosting.com/subs/fastfacts/obesity_youth.shtml (accessed 1 January 2011).

6. Grgurić J. Prevencija debljine počinje u djetinjstvu. Pediatria Croatica 2004;48:35-39.

7. Sweeting H, West P,Young R. Obesity among Scotttish 15 year olds 1987-2006: prevalence and associations with socio-economic status, well-being and worries about weight. BMC Public Health 2008:8:404-410.

8. Lidstone J, Wilkinson JR, Bailey K. Obesity and overweight in Europe and lessons from France and Finland. Discussion Paper. North East Public Health Observatory, Stockton on Tees. http://www.dur.ac.uk/ne.pho/view file.php?c=564 (accessed 1 January 2011).

9. Latner JD, Simmonds M, Rosewall JK, Stunkard AJ. Assessment of obesity stigmatization in children and adolescents: Modernizing a standard measure. Obesity 2007;15:3078-3085.

10. Wardie J. The impact of obesity on psychological well-being. Best Practice and Research in Clinical Endocrinology and Metabolism 2005;19:421-440.

11. ter Bogt TFM, Saskia AFM, van Dorsselaer MA, et al. Body mass index and body weight perception as risk factors for internalizing and externalizing problem behavior among adolescents. J Adolesc Health 2006;39:27-34.

12. Xiaoyan X, Mellor D, Kiehne M, Ricciardelli LA, McCabe MP, Yangang X. Body dissatisfaction, engagement in body change behaviors and sociocultural influences on body image among Chinese adolescents. Body Image 2010;7:156-164

13. Lowry KW, Sallinen BJ, Janicke DM. The effects of weight menagements programs on selfesteem in pediatric overweight populations. J Pediatr Psychol 2007;32:1179-1195.

14. Fowler BA. The relationship of body-image perception and weight status to recent change in weight status of the adolescent female. Adolescence 1989;95:557-568.

15. Lacković-Grgin K. Samopoimanje Mladih. Jastrebarsko: Naklada Slap, 1994

16. Flisher AJ. The school as a setting for child and adolescent mental health interventions. African Journal of Psychiatry 2005;11:77-78.

17. Havighurst RJ. Develpmental Tasks and Education. Chicago, IL: University of Chicago Press, 1948.

18. Nikolić S. Psihijatrija Dječje i Adolescentne Dobi, Propedeutika. Zagreb: Školska Knjiga, 1991:311-344.

19. Swallen KC, Reither EN, Haas SA, Meier AM. Overweight, obesity, and health-related quality 
of life among adolescents: the National Longitudinal Study of Adolescent Health. Pediatrics 2005; 115:340-347.

20. Offer D, Ostrov E, Howard KI, Atkinson R. Normality and adolescence. Psychiatry Clin North Am 1990;13(3):377-388

21. Dittmar $H$, Halliwell E, lve $S$. Does Barbie make girls want to be thin? The effect of experimental exposure to images of dolls on the body image of 5- to 8-year-old girls. Developmental Psychology 2006;42:283-292.

22. Pessa JA, Syre TR, Jones E. Psychosocial differences associated with body weight among female adolescents: the importance of body image. J Adolesc Health 2000;26(5):330-337.

23. Cornette R. The emotional impact of obesity on children. Worldviews on Evidence Based Nursing 2008:5:136-141.

24. Mirza N, Dawnavan D, Yanovski JA. Body dissatisfaction, self-esteem, and overweight among innercity Hispanic children and adolescents. J Adolesc Health 2005;36:267.e16s67.e-20.

25. Bar-Tal D, Saxe L. Physical attractiveness and its relationship to sex role stereotyping. Sex Roles 1976;2:123-133.

26. Thornton B, Ryckman RM. Relationship between attractiveness, physical effectiveness and self-esteem: A cross-sectional analysis among adolescents. J Adolesc 1991;14:85-98.

27. Offer D, Ostrov E, Howard KJ. The Offer Self-Image for Adolescents: A Manual. Chicago: Michael Reese Hospital and Medical Center, 1982

28. Garrick T, Ostrov E, Offer D. Psychical symptoms and self-image in a group of normal adolescents. Psychosomatics 1988;29(1):73-80

29. Postupak odobravanja provođenja kliničkog ispitivanja u Republici Hrvatskoj. Zakon o lijekovima (NN 71/07 | 45/09). Pravilnik o kliničkim ispitivanjima I dobroj kliničkoj praksi (NN 14/10, 127/10). http://narodne-novine.nn.hr (accessed 3 November 2011).

30. Laukkanen E, Halonen P, Aivio A, Viinamaki H, Lehtonen J. Construct validity of the Offe Self-Image Questionnaire in Finnish 13-year-old adolescents: Differences in the self-images of boys and girls. Nord J Psychiatry 2000;54:431-435.

31. Palazzi S, De Vito E, Luzzati D, Guerrini A, Torre E. A study of the relationship between life events and disturbed self image in adolescents. J Adolesc 1990;13:53-63.

32. Offer D, Ostrov E, Howard KI. The Adolescent: A Psychological Self-portrait. New York: Basic Books, 1981.

33. Offer D, Ostrov E, Howard KJ, Atkinson R. The Teenage World - Adolescents' Self Image in Ten Countries. New York: Plenum Medical Book Company, 1989.

34. Kulenović M, Rudan V, Kraljević R. Self-concept of the future medical workers. Collegium Antropologicum 1996;20:331-336
35. Koenig LJ. Self-image of emotionally disturbed adolescents. J Abnorm Child Psychol 1988;16:111-126.

36. Offer D, Ostrov E, Howard KI. The mental health professional's concept of the normal adolescent. Arch Gen Psychiatry 1981;38:149-152.

37. Erkolahti $\mathrm{R}$, Ilonen $\mathrm{T}$, Saarijarvi $\mathrm{S}$, Terho P. Self-image and depressive symptoms among adolescents in a non-clinical sample. Nord J Psychiatry 2003;57:447-451.

38. Fine $S$, Haley G, Gilbert M, Forth A. Self-image as a predictor of outcome in adolescent major depressive disorder. J Child Psychol Psychiatry 1993;34:1399-1407.

39. Hintikka U, Marttunen M, Pelkonen M, Laukkanen E, Vilnamaki H, Lehtonen J. Improvement in cognitive and psychosocial functioning and self image among adoolescent inpatient suicide attempters. BMC Psychiatry 1006;6:58.

40. McGadney P. Differences in adolescent self-concept as a function of race, geographic location and pregnancy. Adolecence 1995;30:95-105.

41. Erkolahti RK, Saarijarvi S, Ilonen T, Hagman H. Self-image of anorexic and bulimic female adolescents. Nord J Psychiatry 2002;56:447-450

42. Siefen K, Kirkcaldy BD, Athanasou JA, Peponis M. The self-image of Greek, Greek-migrant and German adolescents. Soc Psychiatry Psychiatr Epidemiol 1996;31:241-247.

43. Erkolahti R, Ilonen T, Saarijarvi S, Terho P. Self-image and depressive symptoms among adolescents in a non-clinical sample. Nord J Psychiatry 2003;57:447-451.

44. Iniewicz G. Self-image of female adolescents suffering from anorexia nervosa. Psychiatria Polska 2005:39:709-717.

45. Van Vlierberghe L, Breat C, Goossens L, Mels S. Psychiatric disorders and symptom severity in referred versus non-referred overweight children and adolescents. Eur Child Adolesc Psychiatry 2008;18(3):164-173.

46. Drukker M, Wojciechowski F, Feron FJ, Mengelers R, van Os J. A community study of psychosocial functioning and weight in young children and adolescents. Int $J$ Pediatr Obes 2008;16:1-7.

47. Goldschmidt AB, Doyle AC, Wilfley DE. Assessment of binge eating in overweight youth using a questionnaire version of the Child Eating Disorder Examination with Instructions. Int J Eat Disord 2007:40:460-467.

48. Tanofsky-Kraff M, Theim KR, Yanovski SZ, et al. Validation of the emotional eating scale adapted for use in children and adolescents (EES-C). Int J Eat Disord 2007;40:232-240.

49. Bener A, Zewfik I. Prevalence of overweight, obesity, and associated psychological problems in Qatari's female population. Obes Rev 2006:7:139-145. 